\title{
Trends in an Absorption Column through Mass Transfer Coefficients
}

\author{
Ibrahim Mohamed Mahmoud Aboelkheir \\ Aboelkheir Investments, Dubai, United Arab Emirates \\ aboelcare@gmail.com \\ DOI: 10.47760/cognizance.2022.v02i01.003
}

\begin{abstract}
A study was conducted to measure the values of m.t.c and $\mathbf{N}$ of an absorption column. Values of $\mathbf{N}$ were in the range of $\mathbf{1 0 - 5}$, while those of m.t.c were in the range of 10-7. The trends with variables were confirmed with the previous studies. However, they were not with m.t.c. Pressure variance was suggested as the reason. Error was assessed at a percentage of $15 \%$ for m.t.c, and under $2 \%$ for pressure. Using other methods than only measuring concentration of solute with the Hempl apparatus was recommended.
\end{abstract} Keywords- Mass Transfer Coefficient, Chemical Engineering, Carbon Capture, Absorption Column

\section{INTRODUCTION}

Mass transfer of a substance via packed columns is a common extraction process in the chemical industry. Examples include distillation, gas absorption and desorption. In such a process, counterflows of gas and liquid are in contact, of which this allows for a chemical species to transfer from one fluid to another. A mass transfer coefficient can be determined using quantified conditions of the packed tower (Sinnott, et al., 2005). Figure 1 exemplifies on the process with gas absorption.

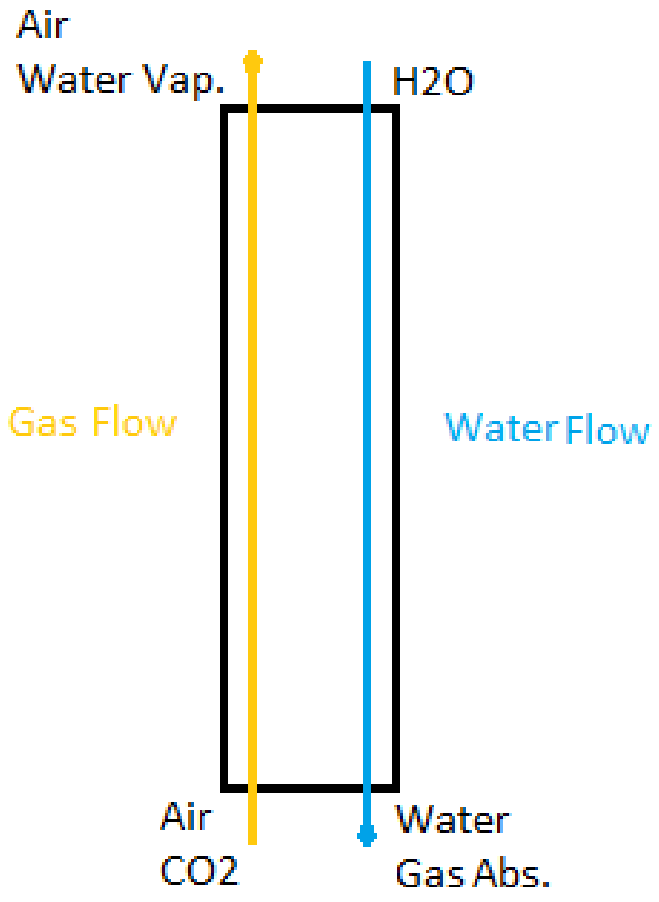

Figure 1. Mass Transfer process in an absorption column 


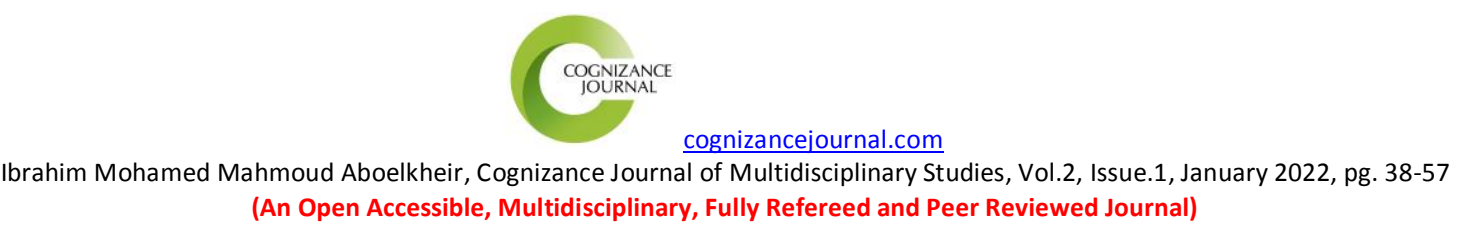

ISSN: 0976-7797

An experiment was conducted on the absorption of $\mathrm{CO} 2$ from air flow into water flow. It was performed through the UOP7 Armfield UOP7 Gas Absorption Column which appears on Figure 2.

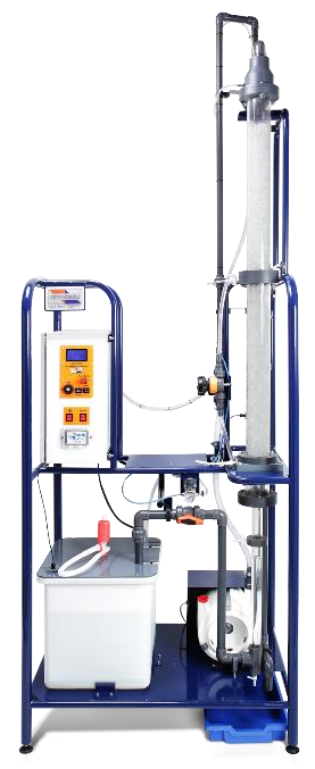

Figure 2 (Armfield, 2020)

The lab exercise done is aimed at calculating the number of moles of absorbed carbon dioxide $(\mathrm{N})$ in provided condition and at determining the mass transfer coefficient (m.t.c) of the absorption column. This is done upon understanding how a packed column works and learning how to operate the column where desired liquid flowrate is maintained against the desired gas flowrate.

Previous studies were performed to find the values of m.t.c on the same system, each of them arriving to the following combination of variables. They are the number of moles absorbed of $\mathrm{CO} 2$, flow rates, partial pressures, volume of the column and the interfacial surface area per unit volume of the packing. Where different parameters where provided, equations were used in the studies to arrive to those aforementioned. The first of these was conducted with the same UOP 7 type, gas and liquid streams as the experiment done. The conditions are presented in the tables and figures below.

Table 1 (Evren, et al., 1999)

\begin{tabular}{|c|c|c|c|}
\hline \multicolumn{4}{|c|}{$K \mathbf{L} \boldsymbol{a}\left(\mathbf{s}^{-\mathbf{1}}\right)$ Per Run } \\
\hline$T\left({ }^{\circ} \mathrm{C}\right)$ & $\boldsymbol{y = 0 . 0 5}$ & $\boldsymbol{y = 0 . 1 0}$ & $\boldsymbol{y}=\mathbf{0 . 2 0}$ \\
\hline 20 & 0.0166 & 0.0184 & 0.0162 \\
\hline 25 & 0.0161 & 0.0158 & 0.0146 \\
\hline 30 & 0.0173 & 0.0163 & 0.0162 \\
\hline
\end{tabular}


cognizancejournal.com

Ibrahim Mohamed Mahmoud Aboelkheir, Cognizance Journal of Multidisciplinary Studies, Vol.2, Issue.1, January 2022, pg. 38-57 (An Open Accessible, Multidisciplinary, Fully Refereed and Peer Reviewed Journal)

ISSN: 0976-7797

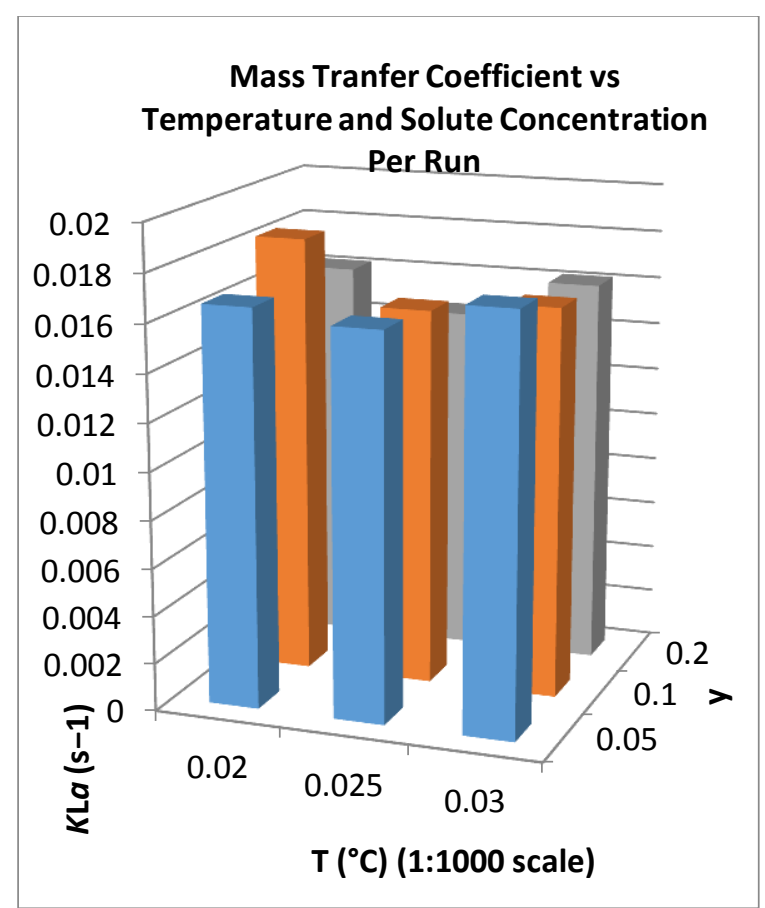

Figure 3

Data from Table 1 indicates that given a constant water flow rate, the overall m.t.c is not significantly affected by temperature and gas inlet concentration. This is observed in Figure 3.

Nonetheless, a link between m.t.c and Liquid Flow Rate can be interpreted from Table 2 (Evren, et al., 1999).

Table 2 (Evren, et al., 1999)

\begin{tabular}{|c|c|c|c|}
\hline \multirow{2}{*}{$\mathbf{L}\left(\mathbf{m}^{3} \mathbf{s}_{-\mathbf{1}}\right)$} & \multicolumn{3}{|c|}{$\boldsymbol{K L} \boldsymbol{a}\left(\mathbf{s}^{-\mathbf{1}}\right)$} \\
\cline { 2 - 4 } & $\boldsymbol{y = 0 . 0 5}$ & $\boldsymbol{y}=\mathbf{0 . 1 0}$ & $\boldsymbol{y}=\mathbf{0 . 2 0}$ \\
\hline $8.33 \times 10-5$ & 0.0116 & 0.0116 & 0.0127 \\
\hline $1.17 \times 10-4$ & 0.0166 & 0.0184 & 0.0162 \\
\hline $1.50 \times 10-4$ & 0.0202 & 0.0212 & 0.0195 \\
\hline
\end{tabular}

The more the liquid flow rate increases, the higher the value of m.t.c becomes. As such, mass transfer then occurs at a higher rate. This relationship is illustrated by Figure 4. 
cognizancejournal.com

Ibrahim Mohamed Mahmoud Aboelkheir, Cognizance Journal of Multidisciplinary Studies, Vol.2, Issue.1, January 2022, pg. 38-57 (An Open Accessible, Multidisciplinary, Fully Refereed and Peer Reviewed Journal)

ISSN: 0976-7797

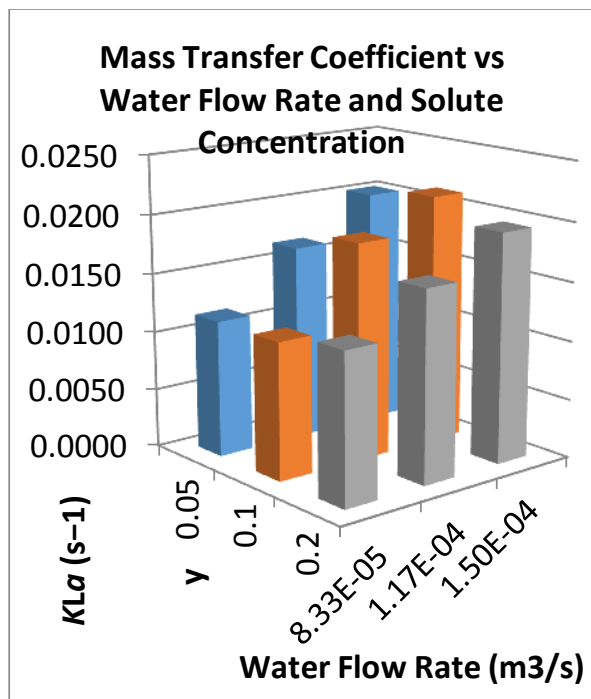

Figure 4

Another study was performed on the same streams and column. The variables are provided in Table 3.

Table 3 (Taylor, et al., 2020)

\begin{tabular}{|c|c|c|c|}
\hline Run & 1 & 2 & 3 \\
\hline Air Flowrate (L/min) & 30 & 30 & 30 \\
\hline CO2 Flowrate (L/min) & 10 & 8 & 4 \\
\hline Water Flowrate (L/min) & 4 & 4 & 4 \\
\hline CO2 Conc. (B) & $23.40 \%$ & $18 \%$ & $9.70 \%$ \\
\hline CO2 Conc. $(\mathrm{T})$ & $20.10 \%$ & $16.60 \%$ & $8.90 \%$ \\
\hline a (m2/m3) & 440 & 440 & 440 \\
\hline$A^{*} \mathbf{Z}(\mathbf{m} 3)$ & 0.0062 & 0.0062 & 0.0062 \\
\hline G (Abs) (m3/sec) & 0.103050982 & 0.046364353 & 0.009558652 \\
\hline N (g*moles/s) & $1.21036 \mathrm{E}-05$ & $5.42726 \mathrm{E}-06$ & $1.11515 \mathrm{E}-06$ \\
\hline $\operatorname{Kog}\left(m^{*} s-1 * P a-2\right)$ & $1.94280 \mathrm{E}-09$ & $8.16097 \mathrm{E}-10$ & $1.81213 \mathrm{E}-10$ \\
\hline
\end{tabular}

Upon comparing m.t.c vs $\mathrm{CO} 2$ flow rate via Figure 5, it becomes clear that the former has a proportional relationship with the latter. This confirms what the prior study discussed regarding flow rates affecting the coefficient. That being said, in the first study the studied flow rate was that of water, while it was that of $\mathrm{CO} 2$ in this study. 
cognizancejournal.com

Ibrahim Mohamed Mahmoud Aboelkheir, Cognizance Journal of Multidisciplinary Studies, Vol.2, Issue.1, January 2022, pg. 38-57

(An Open Accessible, Multidisciplinary, Fully Refereed and Peer Reviewed Journal)

ISSN: 0976-7797

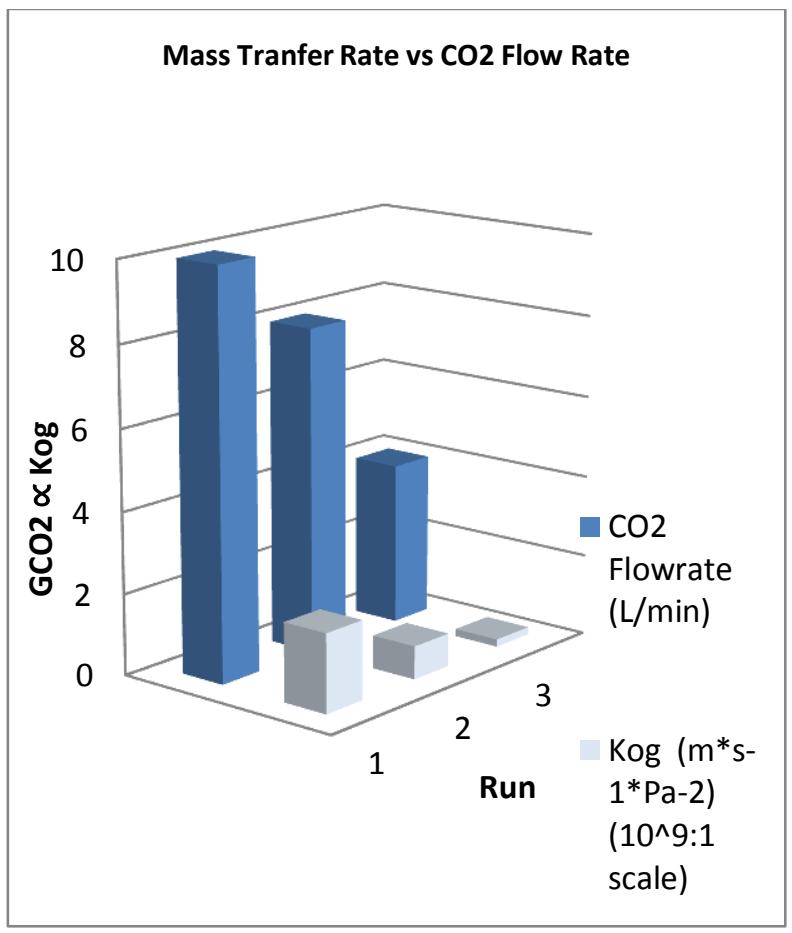

Figure 5

However, a proportionality is found in Figure 6 that contradicts the findings of the first paper. A correlation was found between m.t.c and the given parameters. This could be assessed if gas flow rates of the initial study were provided. Nonetheless, the introduction of theory shall be sufficient for analysis.

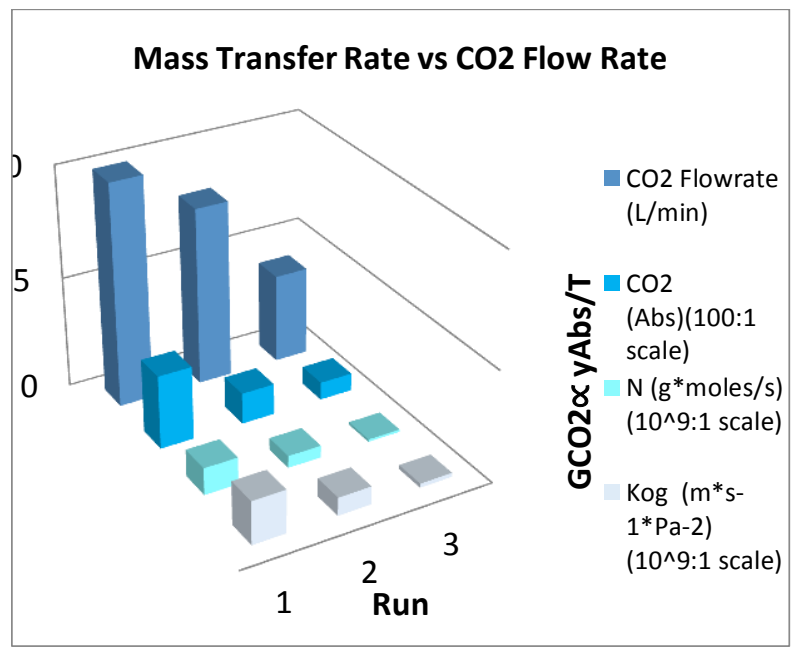

Figure 6 


\section{COGNIZANCE}

cognizancejournal.com

Ibrahim Mohamed Mahmoud Aboelkheir, Cognizance Journal of Multidisciplinary Studies, Vol.2, Issue.1, January 2022, pg. 38-57

(An Open Accessible, Multidisciplinary, Fully Refereed and Peer Reviewed Journal)

ISSN: 0976-7797

\section{THEORETICAL BACKGROUND}

\section{Determining the value of the number of moles absorbed}

The following equation determines the number of moles absorbed (Sinnott, et al., 2005):

$$
\mathrm{N}_{\mathrm{Abs}}=\mathrm{G}_{\mathrm{Abs}} \mathrm{dy}
$$

At the full height of the column, the equation becomes:

$$
\mathrm{N}_{\mathrm{Abs}}=\mathrm{G}_{\mathrm{Abs}}\left(\mathrm{y}_{\mathrm{in}}-\mathrm{y}_{\text {out }}\right)
$$

$\mathrm{y}_{\mathrm{Abs}}$ is by convention as follows:

$$
\mathrm{y}_{\mathrm{Abs}}=\mathrm{y}_{\text {in }}-\mathrm{y}_{\text {out }}
$$

The derivation of GAbs is as follows. yAbs is also known by convention as:

$$
\begin{gathered}
y_{A b s}=\frac{G_{A b s}}{G_{A b s}+L} \\
y_{A b s}=\frac{\frac{G_{A b s}}{L}}{\frac{G_{A b s}}{L}+\frac{L}{L}} \\
y_{A b s}=\frac{Y_{A b s}}{Y_{A b s}+1} \\
Y_{A b s}=\frac{y_{A b s}}{1-y_{A b s}} \\
\frac{G_{A b s}}{L}=\frac{y_{A b s}}{1-y_{A b s}} \\
G_{A b s}=L * \frac{y_{A b s}}{1-y_{A b s}}
\end{gathered}
$$

Hence, the value of NAbs will be calculated as such.

\section{Determination of the Mass Transfer Constant}

The value of m.t.c is as follows:

$$
\mathrm{N}_{\mathrm{Abs}}=\mathrm{G}_{\mathrm{Abs}} \mathrm{dy}
$$

Given the convention for every y:

$$
y=\frac{p}{P}
$$




\section{COGNIZANCE}

cognizancejournal.com

Ibrahim Mohamed Mahmoud Aboelkheir, Cognizance Journal of Multidisciplinary Studies, Vol.2, Issue.1, January 2022, pg. 38-57

(An Open Accessible, Multidisciplinary, Fully Refereed and Peer Reviewed Journal)

$$
\begin{gathered}
d y=\frac{d p}{P} \\
\mathrm{~N}_{\mathrm{Abs}}=\mathrm{G}_{\mathrm{Abs}} \frac{\mathrm{dp}}{\mathrm{P}}
\end{gathered}
$$

Given that:

$$
\begin{gathered}
\mathrm{N}_{\mathrm{Abs}}=\mathrm{k}_{\mathrm{og}} \mathrm{aAP}\left(\mathrm{p}-\mathrm{p}_{\mathrm{e}}\right) \mathrm{dz} \\
\mathrm{dz}=\frac{\mathrm{G}_{\mathrm{Abs}}}{\mathrm{k}_{\mathrm{og}} \mathrm{aAP}} * \frac{\mathrm{dp}}{\left(\mathrm{p}-\mathrm{p}_{\mathrm{e}}\right)} \\
\int_{0}^{\mathrm{Z}} \mathrm{dz}=\frac{\mathrm{G}_{\mathrm{Abs}}}{\mathrm{k}_{\mathrm{og}} \mathrm{aAP}} * \int_{\mathrm{p}_{\text {out }}}^{\mathrm{p}_{\text {in }}} \frac{\mathrm{dp}}{\left(\mathrm{p}-\mathrm{p}_{\mathrm{e}}\right)}
\end{gathered}
$$

As such:

\section{$\mathrm{Z}=\mathrm{HTU} \mathrm{N}^{*} \mathrm{NTU}$}

This is where the height of the column is equal to the height of the theoretical unit multiplied by the number of theoretical units.

Hence, it is integrated as:

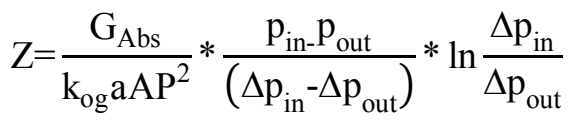

Where:

$$
\begin{gathered}
\Delta \mathrm{p}_{\text {in }}=\left(\mathrm{p}_{\text {in }}-\mathrm{p}_{\mathrm{e}}\right) \\
\Delta \mathrm{p}_{\text {out }}=\left(\Delta \mathrm{p}_{\text {out }}-\mathrm{p}_{\mathrm{e}}\right)
\end{gathered}
$$

If the required values are not available, the equation is approximated as:

$$
\begin{gathered}
\mathrm{Z}=\frac{\mathrm{N}_{\text {Abs }}}{\mathrm{k}_{\text {og }} \mathrm{aA}} * \frac{\ln \frac{\mathrm{p}_{\text {in }}}{\mathrm{p}_{\text {out }}}}{\mathrm{p}_{\text {in }-} \mathrm{p}_{\text {out }}} \\
\mathrm{k}_{\mathrm{og}}=\frac{\mathrm{N}_{\mathrm{Abs}}}{\mathrm{aAZ}} * \frac{\ln \frac{\mathrm{p}_{\text {in }}}{\mathrm{p}_{\text {out }}}}{\mathrm{p}_{\text {in }-} \mathrm{p}_{\text {out }}}
\end{gathered}
$$

If partial pressures are not available, then:

$$
\mathrm{k}_{\mathrm{og}}=\frac{\mathrm{N}_{\mathrm{Abs}}}{\mathrm{aAZ}} * \frac{\ln \frac{\mathrm{Py}_{\text {in }}}{\mathrm{Py}_{\text {out }}}}{\mathrm{Py}_{\text {in }}-\mathrm{Py}_{\text {out }}}
$$




$$
\mathrm{k}_{\mathrm{og}}=\frac{\mathrm{N}_{\mathrm{Abs}}}{\mathrm{aAZP}} * \frac{\ln \frac{\mathrm{y}_{\mathrm{in}, \mathrm{CO}_{2}}}{\mathrm{y}_{\mathrm{out}_{\mathrm{CO}}}}}{\mathrm{y}_{\mathrm{in}, \mathrm{CO}_{2}}-\mathrm{y}_{\mathrm{out}_{2}, \mathrm{CO}_{2}}}
$$

$\mathrm{P}$ is determined by the convention:

$$
\mathrm{P}=\mathrm{P}_{\text {in }}=\frac{\mathrm{F}_{\text {in }}}{\mathrm{A}}=\frac{\mathrm{m}_{\text {in }} \mathrm{g}}{\mathrm{A}}
$$

Where:

$$
\mathrm{m}_{\mathrm{in}}=\left(\mathrm{M}_{\mathrm{W}, \mathrm{Air}} \mathrm{n}_{\mathrm{Air}}\right)+\left(\mathrm{M}_{\mathrm{W}, \mathrm{CO}_{2}} \mathrm{n}_{\mathrm{CO}_{2}}\right)
$$

$\mathrm{n}$ is derived by:

$$
\begin{gathered}
\mathrm{PG}=\mathrm{NRT} \\
\mathrm{PV}=\mathrm{nRT} \\
\frac{\mathrm{NR}}{\mathrm{G}}=\frac{\mathrm{nR}}{\mathrm{V}} \\
\mathrm{n}=\frac{\mathrm{NV}}{\mathrm{G}}
\end{gathered}
$$

$\mathrm{V}$ is determined by the convention:

$$
\begin{gathered}
\mathrm{y}=\frac{\mathrm{V}}{\mathrm{V}_{\mathrm{T}}} \\
\mathrm{V}=\mathrm{y} \mathrm{V}_{\mathrm{T}}
\end{gathered}
$$

\section{EXPERIMENTAL METHOD \& EQUIPMENT}

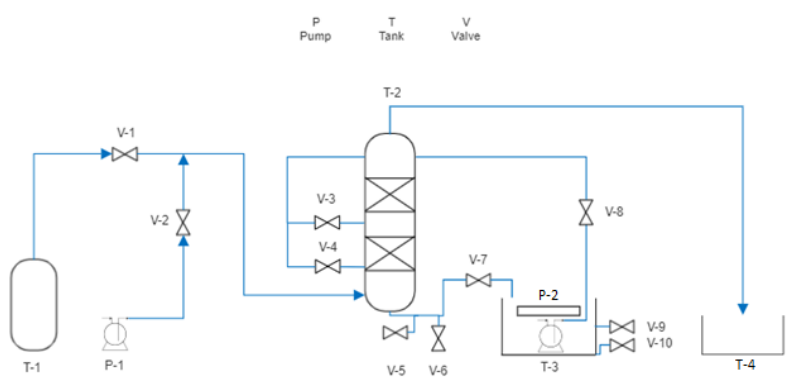

Figure 7. Process Flow Diagram

A PFD was drawn to demonstrate the compartments of the absorption unit (Figure 7). Denotations of the part types are at the top of the figure. The column itself has a height of $1.4 \mathrm{~m}$, and its inside-diameter is $80 \mathrm{~mm}$. The column is composed of two sections packed with $100 \mathrm{~mm} 2$ Raschig rings (see Figure 16 for packing types). Rotameters were 


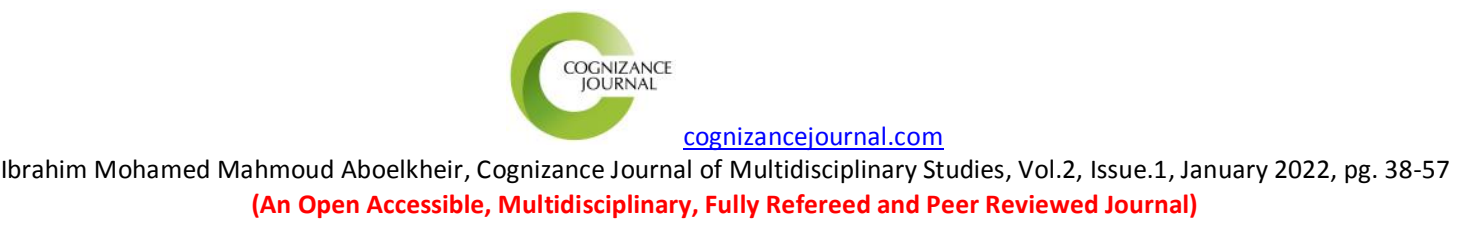

ISSN: 0976-7797

connected in line with the fluid inputs to regulate flowrates. Low compressors were connected close to the gas inputs to control flowrates. A Hempl apparatus was provided to enumerate the $\mathrm{CO} 2$ Content in the gas (see Figure 8). For the purpose of the experiment done, some valves were unused.

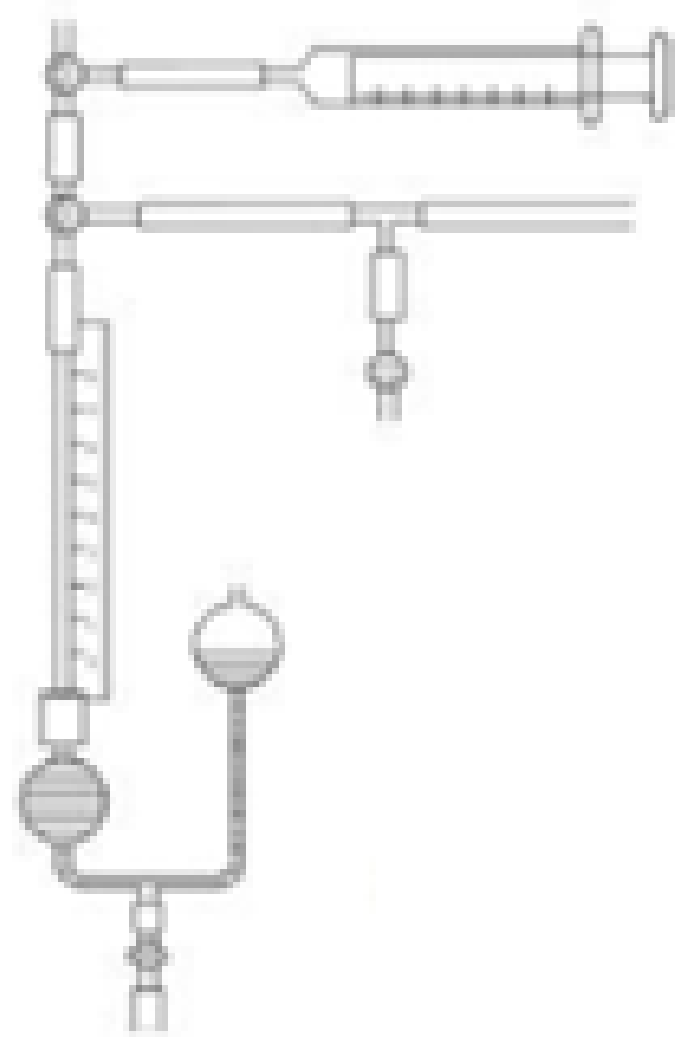

Figure 8 (Armfield LTD., 2010)

The experiment was started by assuring that the Hempl apparatus has been filled with one mole of $\mathrm{NaOH}$. The levels in the globe were checked to be at the 0 mark on the scale. Parallax error could have occurred at $\pm 1 \%$ accuracy. Valve 9 was switched on to fill Tank 3. Valve 6 was switched one to drain the water output. With the other valves closed, Pump 2 was started and the water flow was regulated to 4 Liters/min via valve 8 . The Air compressor was turned on, and valve 2 was adjusted to $30 \mathrm{~L} / \mathrm{min}$.

Valves and rotameters could present a mechanical error where the value regulated to might be off. Calculation is needed for so. The pressure regulating valve 1 for $\mathrm{CO} 2$ Tank 1 was opened and adjusted to a flowrate. The liquid seal of Tank 3, Valve 7 and Valve 10 were checked to be closed. Samples of the CO2 content were taken and measured using the Hempl apparatus. This was done after 5-10 minutes of steady operation. These steps were redone on CO2 runs with flowrates of 10,8,6 and $4 \mathrm{~L} / \mathrm{min}$. This was performed over two sets. The height of the column and packing area were given. Table 4 below demonstrates the input. 
cognizancejournal.com

Ibrahim Mohamed Mahmoud Aboelkheir, Cognizance Journal of Multidisciplinary Studies, Vol.2, Issue.1, January 2022, pg. 38-57 (An Open Accessible, Multidisciplinary, Fully Refereed and Peer Reviewed Journal)

ISSN: 0976-7797

Table 4

\begin{tabular}{|l|c|c|c|c|}
\hline Run & $\mathbf{1}$ & $\mathbf{2}$ & $\mathbf{3}$ & $\mathbf{4}$ \\
\hline Air Flowrate (L/min) & 30 & 30 & 30 & 30 \\
\hline $\begin{array}{l}\text { CO2 Flowrate } \\
\text { (L/min) }\end{array}$ & 10 & 8 & 6 & 4 \\
\hline $\begin{array}{l}\text { Water Flowrate } \\
(\mathbf{L} / \mathbf{m i n})\end{array}$ & 4 & 4 & 4 & 4 \\
\hline $\mathbf{a ~ ( m 2 / m 3 )}$ & 440 & 440 & 440 & 440 \\
\hline $\mathbf{A} * \mathbf{Z ~ ( m 3 )}$ & 0.0062 & 0.0062 & 0.0062 & 0.0062 \\
\hline
\end{tabular}

\section{RESULTS \& DISCUSSION}

The molecular weights were taken from a paper done on Molecular weights (Coplen \& Shrestha, 2019).

Calculations were done using the attached excel document.

\section{$N$ Value Results}

Table 5 below shows the calculated values of $\mathrm{N}$ for set 1 . Correlations with flowrate and mole concentration can be noticed.

Table $5 \mathrm{~N}$ values for set 1

\begin{tabular}{|l|c|c|c|c|}
\hline Run & $\mathbf{1}$ & $\mathbf{2}$ & $\mathbf{3}$ & $\mathbf{4}$ \\
\hline $\begin{array}{l}\text { CO2 Flowrate } \\
\text { (L/min) }\end{array}$ & 10 & 8 & 6 & 4 \\
\hline $\begin{array}{l}\text { Set 1 CO2 } \\
\text { (Abs) (mole\%) }\end{array}$ & $1.90 \%$ & $2.00 \%$ & $\begin{array}{c}1.30 \\
\%\end{array}$ & $0.90 \%$ \\
\hline $\begin{array}{l}\text { N (Abs) } \\
\text { (moles/s) }\end{array}$ & $\begin{array}{c}2.45 \mathrm{E}- \\
08\end{array}$ & $\begin{array}{c}2.72 \mathrm{E}- \\
08\end{array}$ & $\begin{array}{c}1.14 \mathrm{E} \\
-08\end{array}$ & $\begin{array}{c}5.44 \mathrm{E}- \\
09\end{array}$ \\
\hline
\end{tabular}

Table 6 indicates similar trends to the previous set. The lower the flowrate is, the lower the number of absorbed moles (moles/s) was. The graphs below illustrate so.

Table $6 \mathrm{~N}$ values for set 2

\begin{tabular}{|l|c|c|c|c|}
\hline Run & $\mathbf{1}$ & $\mathbf{2}$ & $\mathbf{3}$ & $\mathbf{4}$ \\
\hline $\begin{array}{l}\text { CO2 Flowrate } \\
\text { (L/min) }\end{array}$ & 10 & 8 & 6 & 4 \\
\hline $\begin{array}{l}\text { Set 2 CO2 } \\
\text { (Abs) (mole\%) }\end{array}$ & $2.00 \%$ & $1.70 \%$ & $1.20 \%$ & $1.00 \%$ \\
\hline $\begin{array}{l}\text { N (Abs) } \\
\text { (moles/s) }\end{array}$ & $\begin{array}{c}2.72 \mathrm{E} \\
-08\end{array}$ & $\begin{array}{c}1.95 \mathrm{E}- \\
08\end{array}$ & $\begin{array}{c}9.71 \mathrm{E}- \\
09\end{array}$ & $\begin{array}{c}6.73 \mathrm{E}- \\
09\end{array}$ \\
\hline
\end{tabular}

Figure 9 shows a proportional correlation between mole fraction and flow rate. It appears that the value of Set 1 Run 2 flowrate is out of the trend. It shall be discussed in error. 
cognizancejournal.com

Ibrahim Mohamed Mahmoud Aboelkheir, Cognizance Journal of Multidisciplinary Studies, Vol.2, Issue.1, January 2022, pg. 38-57 (An Open Accessible, Multidisciplinary, Fully Refereed and Peer Reviewed Journal)

ISSN: 0976-7797

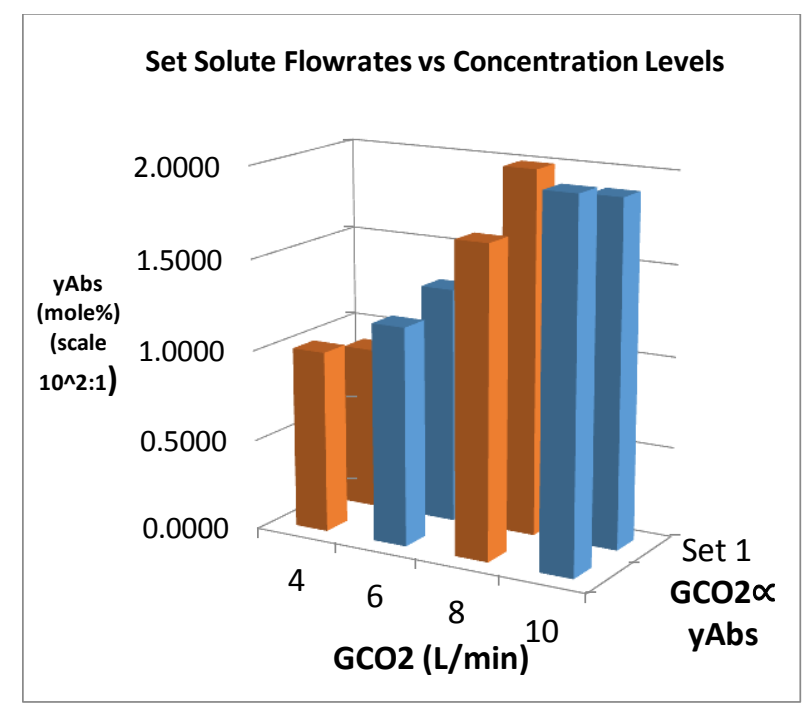

Figure 9

Figure 10 shows a similar trend with flowrate of the solute and the Number of moles absorbed (moles/s). The same trend error can be noted.

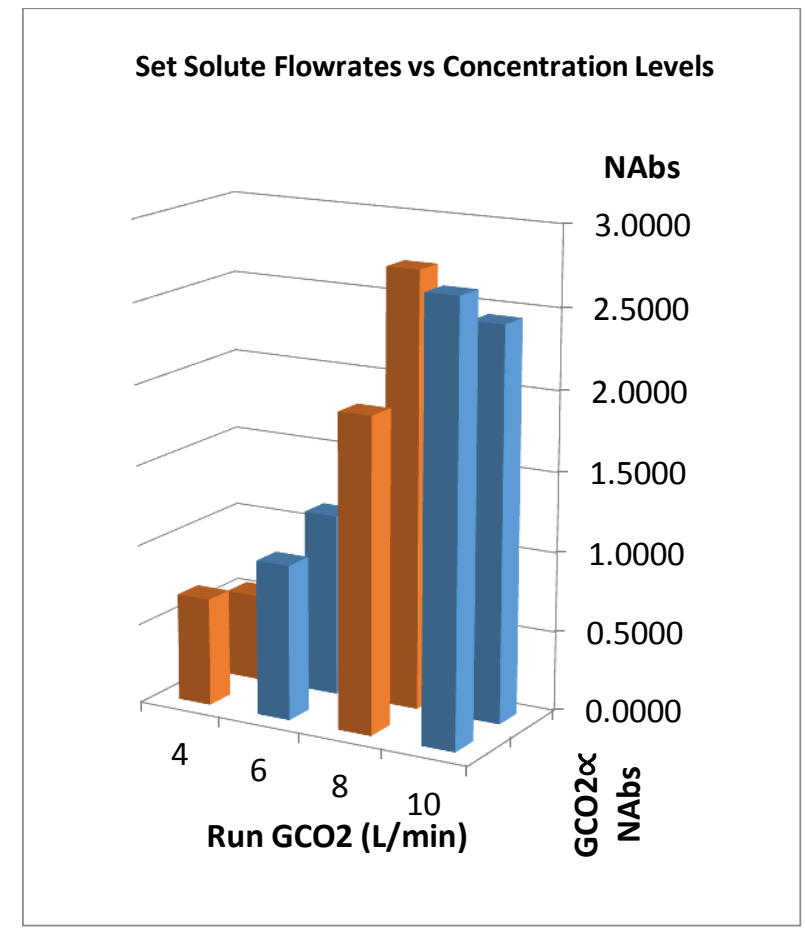

Figure 10

Overall, the findings regarding $\mathrm{N}$ confirm the 2 studies mentioned in the introduction. Found error, nonetheless, can affect finding trends in the following results. 
cognizancejournal.com

Ibrahim Mohamed Mahmoud Aboelkheir, Cognizance Journal of Multidisciplinary Studies, Vol.2, Issue.1, January 2022, pg. 38-57

(An Open Accessible, Multidisciplinary, Fully Refereed and Peer Reviewed Journal)

ISSN: 0976-7797

\section{m.t.c Results}

Tables 7 and 8 both show a trend between pressure and flowrate of solute. This appears in the graphs below as well. Nonetheless, there appears to be no correlation between m.t.c and any parameter. A quick look at the equation used demonstrates that, with stable pressure, the higher the value of $\mathrm{N}$ was, the higher the value of m.t.c was. However, the values of it are not close. This error will be discussed.

\begin{tabular}{|l|c|c|c|c|}
\hline Run & $\mathbf{1}$ & $\mathbf{2}$ & $\mathbf{3}$ & $\mathbf{4}$ \\
\hline $\begin{array}{l}\text { CO2 Flowrate } \\
\text { L/min) }\end{array}$ & 10 & 8 & 6 & 4 \\
\hline $\mathbf{P}(\mathbf{P a})$ & 0.08063 & 0.06699 & 0.04935 & 0.03566 \\
\hline $\begin{array}{l}\text { Kog (m*s- } \\
\mathbf{1 * P a - 2 )}\end{array}$ & $\begin{array}{c}5.43 \mathrm{E}- \\
07\end{array}$ & $\begin{array}{c}8.87 \mathrm{E}- \\
07\end{array}$ & $\begin{array}{c}6.87 \mathrm{E}- \\
07\end{array}$ & $\begin{array}{c}6.33 \mathrm{E}- \\
07\end{array}$ \\
\hline
\end{tabular}

Table 8

\begin{tabular}{|l|c|c|c|c|}
\hline Run & 1 & 2 & 3 & 4 \\
\hline $\begin{array}{l}\text { CO2 Flowrate } \\
\text { (L/min) }\end{array}$ & 10 & 8 & 6 & 4 \\
\hline P $($ Pa) & $\mathbf{0 . 0 8 1 7 5}$ & $\mathbf{0 . 0 6 4 0 5}$ & $\mathbf{0 . 0 4 8 9 8}$ & $\mathbf{0 . 0 3 4 5 4}$ \\
\hline $\begin{array}{l}\text { Kog }\left(m^{*} \text { s- }\right. \\
\text { 1*Pa-2) }\end{array}$ & $\begin{array}{c}5.87 \mathrm{E}- \\
07\end{array}$ & $\begin{array}{c}6.95 E- \\
07\end{array}$ & $\begin{array}{c}5.92 E- \\
07\end{array}$ & $\begin{array}{c}\mathbf{8 . 4 2 E}- \\
07\end{array}$ \\
\hline
\end{tabular}

The mass transfer coefficient values in Figure 11 Are not stable. It is likely that the flow rate increase is dampened by pressure increase.

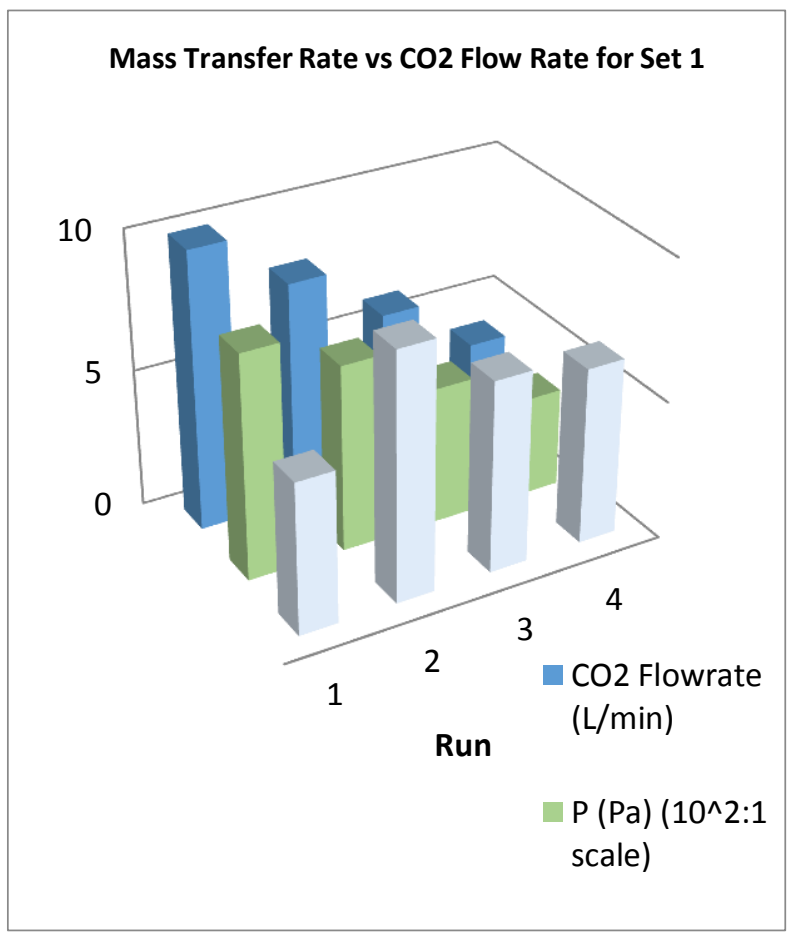

Figure 11 


\section{COGNIZANCE
JOURNAL}

cognizancejournal.com

Ibrahim Mohamed Mahmoud Aboelkheir, Cognizance Journal of Multidisciplinary Studies, Vol.2, Issue.1, January 2022, pg. 38-57 (An Open Accessible, Multidisciplinary, Fully Refereed and Peer Reviewed Journal)

ISSN: 0976-7797

The same is noted with Figure 12.

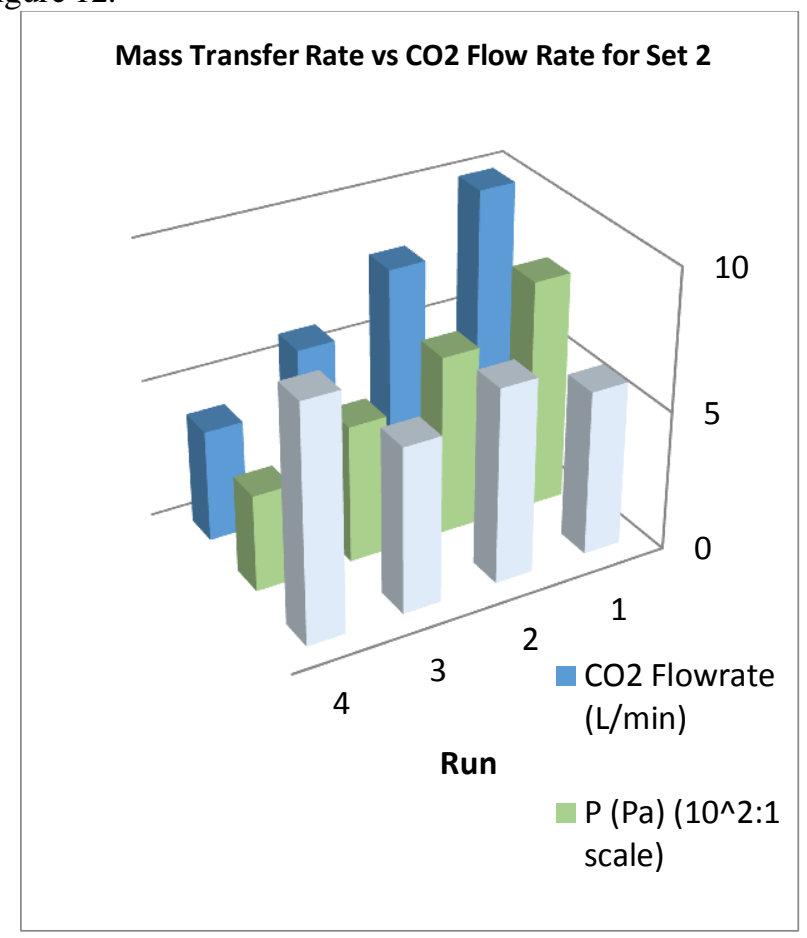

Figure 12

\section{Error Assessment}

Upon comparing the coefficients of Set 1 and 2 in Figure 13, a very subtle correlation can be made.

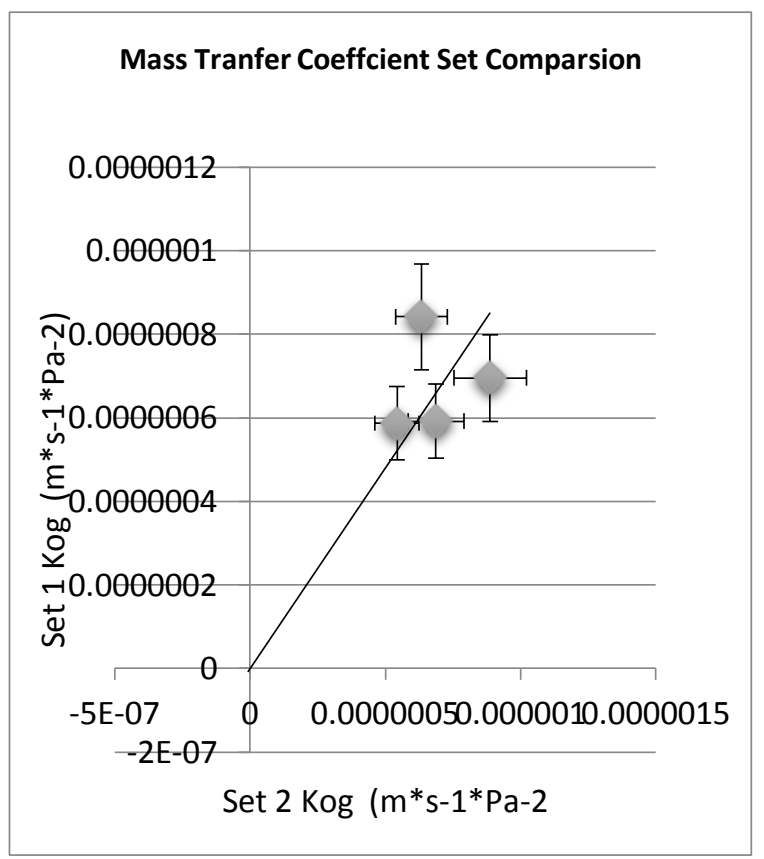

Figure 13 
cognizancejournal.com

Ibrahim Mohamed Mahmoud Aboelkheir, Cognizance Journal of Multidisciplinary Studies, Vol.2, Issue.1, January 2022, pg. 38-57 (An Open Accessible, Multidisciplinary, Fully Refereed and Peer Reviewed Journal)

The out of range value noticed in Figure 9 will be taken off first.

Bars for 15\% error have been assigned to Figure 14. Using them, the values of m.t.c between Set 1 and 2 appear to slightly increase with flowrate. It can be confidently said that the pressure variance has an effect on the values. The Error noticed above, however, can be attributed to pressure or flowrate. A look at the pressure error Figure 15 is needed.

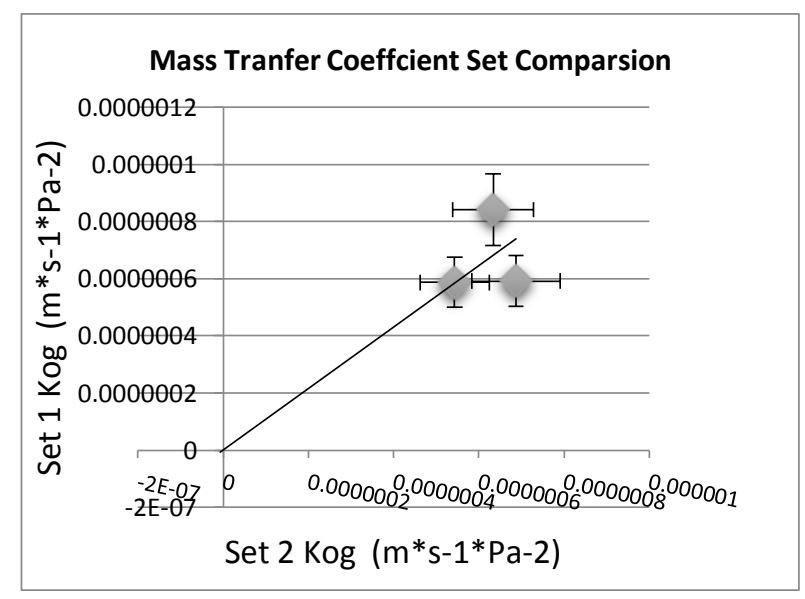

Figure 14

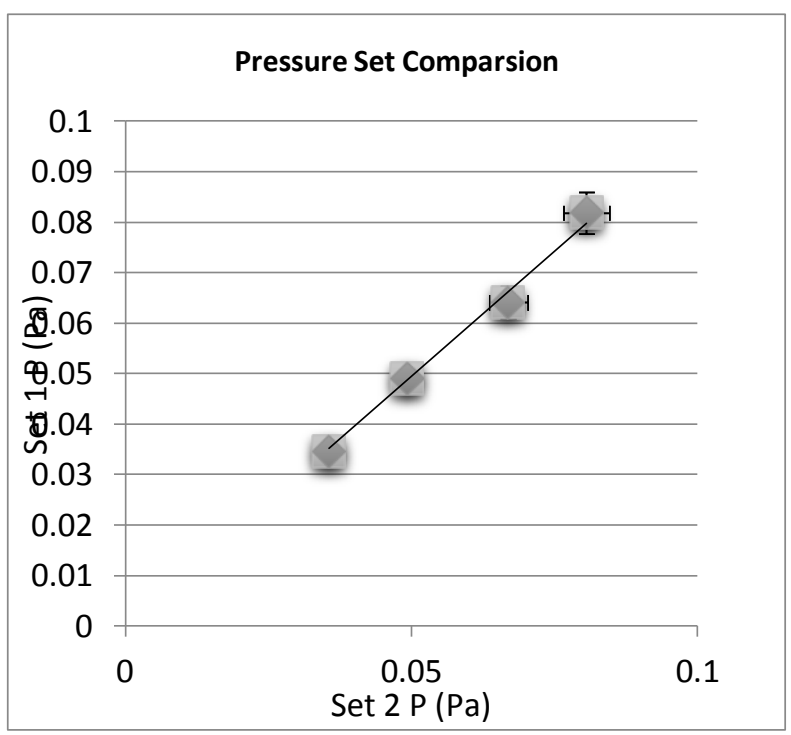

Figure 15 


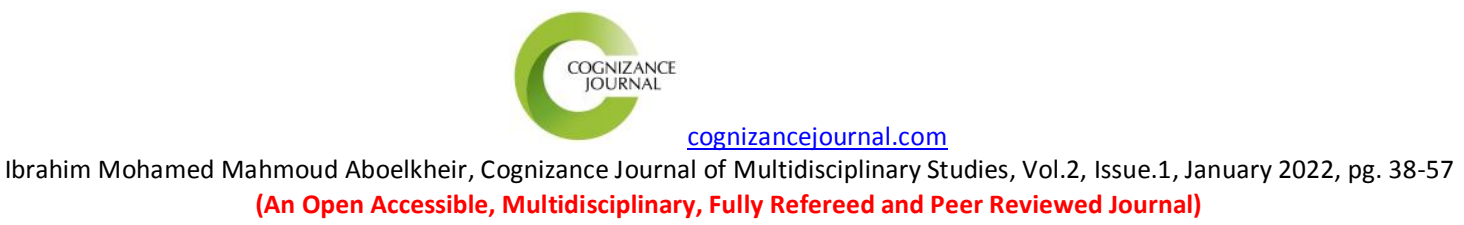

ISSN: 0976-7797

Furthermore, Pressure error is estimated to be $2 \%$. With the pressure values following an accurate trend, The only variable subject to these high error percentages is the mole concentration of absorbed $\mathrm{CO} 2$. It is very sensitive to changes in input, due to its numerous presence in the formed equation for m.t.c. Use of Hempl apparatus inaccurately is a common human error joined with the possibility of parallax error.

It is to be noted that machine error can occur with the flowrate values. However, due to not finding much error, it is safe to assume that they were accurate. The use of the approximated equation on the other hand can share in the inaccuracy of m.t.c. However, all values were calculated using it, and so that error value is not existent in the data.

The studies done previously can be compared with the experiment done. For example, the values in Table 3 for m.t.c are in the decimal range of 10-9. Values in this experiment are in the ranges of 10-7. This can be attributed to calculation error. Reader's observance of both calculations of this experiment and the prior study is needed.

\section{RECOMMENDATIONS}

More precise and accurate methods of measuring $\mathrm{y}_{\mathrm{Abs}}$ are advised in future trials. Acquiring more machine measured parameters is recommended as well to reduce complied error.

\section{CONCLUSION}

To conclude, values of $\mathrm{N}$ were in the range of $10^{-5}$, while those of m.t.c were in the range of 10-7. The trends with parameters were confirmed with the previous studies. However, they were not with m.t.c. Pressure variance was suggested as the reason. Error was assessed at a percentage of $15 \%$ for m.t.c, and under $2 \%$ for pressure. Using other methods than only measuring concentration of solute with the Hempl apparatus was recommended.

\section{INDUSTRY APPLICATIONS}

In the many industry applications, many types of packing are used in the columns. Some of them are below. Figure 16 shows types of packing that industrial absorption towers enclose.

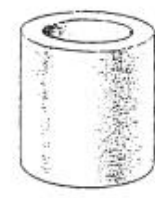

Cerami
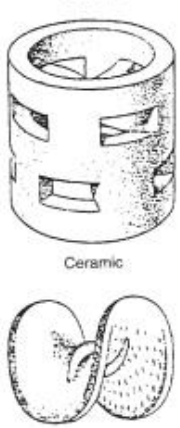

(c)

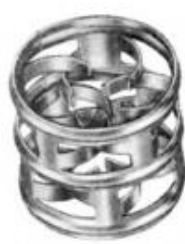

(e)

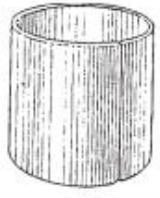

Metal
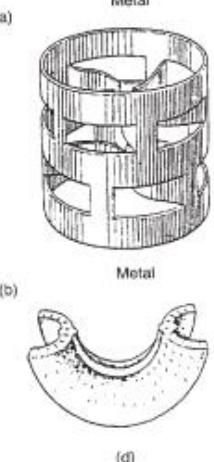

(ब)

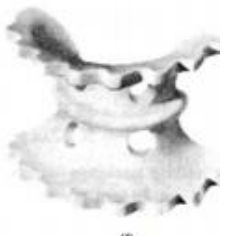

(1)

Figure 16. Types of packing. (a) Raschig rings (b) Pall rings (c) Berl saddle ceramic (d) Intalox saddle ceramic (e) Metal Hypac (f) Ceramic, super Intalox (Sinnott, et al., 2005). 


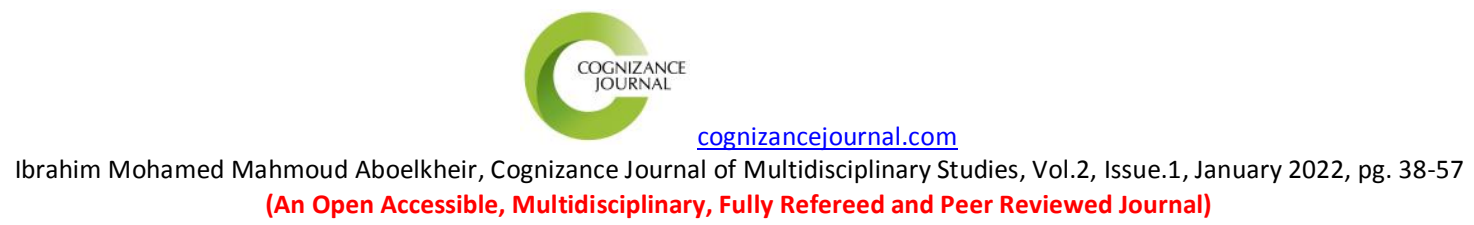

ISSN: 0976-7797

As for the columns, absorption columns are commonly used as scrubbers. They help reduce pollution by capturing solute pollutants. The absorbed species can then be stored or disposed of (Mcmahon, 2020). In chemical processing small absorption towers are used in food refrigeration. Water desiccant removal is utilized in the industry by absorption towers. These silica or alumina based solutes are contained in water and then absorbed using the tower. Natural gas can then leave the tower clean (Reed, 2020). Overall, absorption columns are highly used in the industry. The tables from this experiment can guide industrial design of absorption columns that operate within similar parameters.

\section{SUSTAINABILITY}

Within the context of the lab experiment performed, absorption columns act as a recovery unit of solute. The extraction of $\mathrm{CO} 2$ from the gas stream helps avoid the spread of this pollutant into the environment. This is common in the industry (Mcmahon, 2020). This helps save the ozone layer.

RISK ASSESSMENT

\begin{tabular}{|l|l|l|l|}
\hline Activity: & Gas Absorption & $\begin{array}{l}\text { Assessment } \\
\text { Number: }\end{array}$ & SoE/SRA/ \\
\hline Location: & B1.26 & & \\
\hline
\end{tabular}

\section{Process Description:}

Mass transfer of a substance via packed columns is a common extraction process in the chemical industry. Examples include distillation, gas absorption and desorption. In such a process, counterflows of gas and liquid are in contact, of which this allows for a chemical species to transfer from one fluid to another. A mass transfer coefficient can be determined using quantified conditions of the packed tower (Sinnott, et al., 2005). Figure 1 exemplifies on the process with gas absorption. 
cognizancejournal.com

Ibrahim Mohamed Mahmoud Aboelkheir, Cognizance Journal of Multidisciplinary Studies, Vol.2, Issue.1, January 2022, pg. 38-57

(An Open Accessible, Multidisciplinary, Fully Refereed and Peer Reviewed Journal)

ISSN: 0976-7797

\section{People Involved:}

\begin{tabular}{|l|l|l|l|l|}
\hline Employee & Student & Disabled & Young Person & Pregnant woman \\
\hline Yes & Yes & & & \\
\hline
\end{tabular}

\section{Hazards Identified:}

1. Electrical integrity

2. Spillage

3. $\mathrm{CO}_{2}$ intoxication

4. Risk of Explosion

5. Moving Parts

6. Breakage

\section{LIKELIHOOD $X$ SEVERITY}

1. Extremely Unlikely

1. Minor injury with no

2. Unlikely

3. Likely

days lost

4. Very Likely

5. Almost Certain

lost

\begin{tabular}{|l|l|l|l|l|l|}
\hline \multicolumn{7}{|c|}{ SEVERITY } \\
\hline $\begin{array}{l}\text { LIKELIHOO } \\
\text { D }\end{array}$ & $\begin{array}{l}\mathbf{1 .} \\
\begin{array}{c}\text { Min } \\
\text { or }\end{array}\end{array}$ & $\begin{array}{l}\mathbf{2 . ~ U p ~ t o ~ 3 ~} \\
\text { days }\end{array}$ & $\mathbf{3 . 3}$ days & $\begin{array}{l}\text { 4. } \\
\text { Maj } \\
\text { or }\end{array}$ & 5. Death \\
\hline $\begin{array}{l}\text { 1. Ext. } \\
\text { Unlikely }\end{array}$ & 1 & 2 & 3 & 4 & 5 \\
\hline 2. Unlikely & 2 & 4 & 6 & 8 & 10 \\
\hline 3. Likely & 3 & 6 & 9 & 12 & 15 \\
\hline 4. Very Likely & 4 & 8 & 12 & 16 & 20 \\
\hline $\begin{array}{l}\text { 5. Almost } \\
\text { Certain }\end{array}$ & 5 & 10 & 15 & 20 & 25 \\
\hline & SIGNIFICANT & HIGHEST PRIORITY \\
\hline
\end{tabular}




\begin{tabular}{|l|l|l|l|}
\hline \multicolumn{2}{|c|}{ Risks Identified: } & \multicolumn{2}{c|}{ Risk Rating } \\
\cline { 3 - 4 } & \multicolumn{2}{|c|}{ Severity } & \multicolumn{2}{c|}{ Likelihood } & \multicolumn{2}{c|}{} \\
\hline & & 5 & 20 \\
1. Electrical Shock & 4 & 4 & 12 \\
2. Slips and falls & 3 & 2 & 10 \\
3. Gas leak & 5 & 2 & 8 \\
4. Explosion & 4 & 3 & 3 \\
5. HAVS (hand arm vibration syndrome), risk of getting & 3 & 3 & \\
hands caught & & & \\
6. Cuts & & & \\
\hline
\end{tabular}

\section{Control Measures In Place:}

1. RCD - residual current device (monitors current leakage up to $30 \mathrm{~mA}$ )

2. Mop and paper towel

3. Gas pressure gauge on gas canister

4. Gas pressure gauge on gas canister

5. Students are made aware of the dangers of handling/going near pumps

6. PPE

\begin{tabular}{|l|l|}
\hline \multicolumn{2}{|c|}{ Specified Control Measures for Young person, Pregnant Person or Disabled: } \\
\hline & \\
\hline
\end{tabular}

\section{Do any specific regulations apply to the hazard?}

Health and Safety at work 1974

$\mathrm{COSHH}$

\section{Training Provided:}

Risk assessment training by the academics 
cognizancejournal.com

Ibrahim Mohamed Mahmoud Aboelkheir, Cognizance Journal of Multidisciplinary Studies, Vol.2, Issue.1, January 2022, pg. 38-57

(An Open Accessible, Multidisciplinary, Fully Refereed and Peer Reviewed Journal)

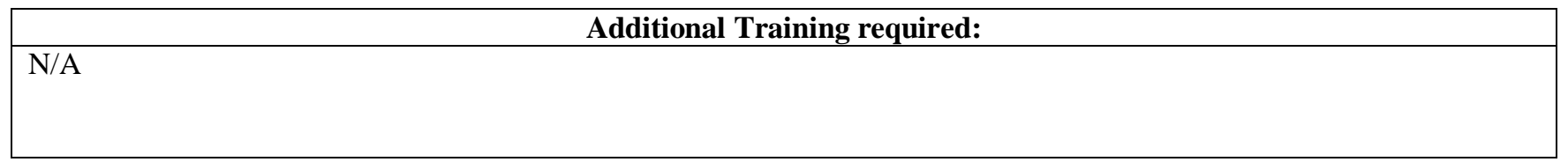

\section{PPE Requirements:}

\section{Lab Coats}

Goggles

Environmental Monitoring:

External Room temperature

\begin{tabular}{|l|l|}
\hline Health Monitoring: \\
\hline N/A
\end{tabular}

\section{Keeping walkways clear}

Safe System of Work:

No clutter

No overcrowding of equipment

Lab protection worn at all times

\begin{tabular}{|l|l|l|l|}
\hline \multicolumn{2}{|c|}{ Level of Risk After Applying Control Measures: } & \multicolumn{3}{|c|}{ Risk Rating } \\
\cline { 3 - 4 } & Severity & Likelihood & Total \\
\hline 1. Electrical Shock & 4 & 1 & 4 \\
2. Slips and falls & 3 & 2 & 6 \\
3. Gas leak & 5 & 1 & 5 \\
4. Explosion & 4 & 1 & 4 \\
5. HAVS (hand arm vibration syndrome), risk of getting hands caught & 3 & 1 & 3 \\
Cuts & 5 & 1 & 5 \\
\hline \multicolumn{1}{|c|}{ Sources of Information: } \\
\hline Provision and Use of Work Equipment Regs/guidance \\
Manufacturers guidelines Observation, staff experience, safety officer \\
MSDS
\end{tabular}


cognizancejournal.com

Ibrahim Mohamed Mahmoud Aboelkheir, Cognizance Journal of Multidisciplinary Studies, Vol.2, Issue.1, January 2022, pg. 38-57 (An Open Accessible, Multidisciplinary, Fully Refereed and Peer Reviewed Journal)

ISSN: 0976-7797

\begin{tabular}{|c|c|c|c|c|c|c|}
\hline \multicolumn{7}{|c|}{ Additional Assessments required: } \\
\hline & $\begin{array}{l}\text { Manual } \\
\text { Handling }\end{array}$ & PPE & $\begin{array}{l}\text { Young } \\
\text { Person }\end{array}$ & $\begin{array}{l}\text { Pregnan } \\
\text { t } \\
\text { Woman }\end{array}$ & $\begin{array}{l}\text { Disabled } \\
\text { Person }\end{array}$ & CoSHH \\
\hline Tick as appropriate & $\checkmark$ & $\checkmark$ & & & & $\checkmark$ \\
\hline
\end{tabular}

\section{Assessment Carried Out By:}

\begin{tabular}{|l|l|l|l|l|l|}
\hline \multicolumn{1}{|c|}{ Assessor: } & \multicolumn{1}{|c|}{$\begin{array}{l}\text { Ibrahim } \\
\text { Aboelkheir }\end{array}$} & \multicolumn{1}{c|}{ Date: } & 31/01/20 & Position: & Student \\
\hline Reviewed: & & Date: & & Position: & \\
\hline Revision: & & $\begin{array}{c}\text { Review } \\
\text { Date: }\end{array}$ & & & \\
\hline
\end{tabular}

\section{REFERENCES}

[1] Armfield LTD., 2010. Product and Teaching Manual for UOP7 - Gas Absorption Column. Armfield Ltd., Issue 21.

[2] Armfield, 2020. UOP7 MKII. [Online] Available at: https://armfield.co.uk/product/uop7-mkii-gasabsorption-column/ [Accessed 26 July 2020].

[3] Coplen, T. B. \& Shrestha, Y., 2019. Erratum to: Isotope-abundance variations and atomic weights of selected elements: 2016 (IUPAC Technical Report). Pure and Applied Chemistry, 91(1), pp. 173-173.

[4] Evren, V., Çağatay, T. \& Özdural, A. R., 1999. Carbon dioxide-air mixtures: mass transfer in recycling packed-bed absorption columns operating under high liquid flow rates. Separation and Purification Technology, 17(2), pp. 89-96.

[5] Mcmahon, M., 2020. What is an Absorption Tower?. [Online] Available at: https://www.wisegeek.com/what-is-an-absorption-tower.htm\#comments [Accessed 28 July 2020].

[6] Reed, P., 2020. What Is the Absorption Process?. [Online] Available at: https://www.wisegeek.com/whatis-the-absorption-process.htm [Accessed 28 July 2020].

[7] Sinnott, R. K., Coulson, J. \& Richardson, J., 2005. Chemical engineering design. 4 ed. Oxford: Elsevier Butterworth-Heinemann.

[8] Taylor, C. et al., 2020. Gas Absorption Lab Report, Bradford: University of Bradford.

[9] University of Florida Chemical Engineering Department, 2020. Unit Operations Lab - Gas Absorption. [Online] Available at: $\quad$ http://ww2.che.ufl.edu/unit-ops-lab/experiments/GA/GA-safety.pdf [Accessed 28 July 2020]. 